\title{
Editorial \\ Predicting joint damage in rheumatoid arthritis using MRI scanning
}

\author{
Fiona M McQueen ${ }^{1}$ and Nicola Dalbeth ${ }^{2}$
}

\begin{abstract}
${ }^{1}$ Associate Professor in Rheumatology, Department of Molecular Medicine and Pathology, Faculty of Medicine and Health Sciences, University of Auckland, 85 Park Rd, Grafton, Auckland, New Zealand

${ }^{2}$ Senior Lecturer in Rheumatology, Department of Medicine, Faculty of Medicine and Health Sciences, University of Auckland, 85 Park Rd, Grafton, Auckland, New Zealand
\end{abstract}

Corresponding author: Fiona M McQueen, f.mcqueen@auckland.ac.nz

Published: 14 September 2009

Arthritis Research \& Therapy 2009, 11:124 (doi:10.1186/ar2778)

This article is online at http://arthritis-research.com/content/11/5/124

(C) 2009 BioMed Central Ltd

See related research by Munwiler et al., http://arthritis-research.com/content/11/3/R94

\begin{abstract}
Predicting prognosis in the patient with newly diagnosed rheumatoid arthritis is of key importance so that high-cost therapies can be tailored to the needs of the individual. In a recent issue of Arthritis Research and Therapy, the prognostic significance of MRI changes at the forefoot has been studied. While progression to radiographic erosion occurred rarely in this group of patients exposed to potent disease-suppressing therapies, including TNF inhibitors, MRI bone edema, representing osteitis, has been further implicated as a forerunner to bone erosion. Early MRI scans of the forefoot were helpful in defining those with the potential to progress as well as those in a good prognosis category.
\end{abstract}

In a recent issue of Arthritis Research and Therapy, Mundwiler and colleagues [1] have investigated the prognostic significance of magnetic resonance imaging (MRI) changes at the forefoot in patients with early rheumatoid arthritis (RA). While there is already an extensive literature investigating the hand and wrist in this context [2-4], much less information exists regarding the forefoot, where radiographic (XR) changes appear early [5]. A previous study has indicated that MRI synovitis, bone edema and erosion can be detected within weeks of the onset of symptoms [6], and of these features, bone edema has repeatedly been shown to be the most important predictor of future erosions at the wrist [2-4]. It is therefore timely to examine the importance of MRI scanning of the feet, using a longitudinal study design to define early prognostic markers.

Mundwiler and colleagues set out primarily to determine the sensitivity, specificity, and predictive value of MRI erosions at individual metatarsophalangeal (MTP) joints for the development of new XR erosions after 6, 12, and 24 months. Secondary objectives were to determine the prognostic significance of MRI synovitis and bone edema and to examine the persistence of those findings over time. Their cohort of patients differed from those studied by McQueen and colleagues [2] in that almost half $(46 \%)$ had received anti-TNF therapy and were, therefore, representative of a modern RA population receiving aggressive management in the biologics era. Comparing their results with those of previous similar studies is a most interesting exercise. At first glance they might seem to be contradictory as the presence of an MRI erosion at baseline had a low positive predictive value for the later development of an XR erosion at that site $(0.17$ at 24 months). However, the negative predictive value was extremely high at 0.99 , virtually guaranteeing that, in its absence, an XR erosion would not develop. This is a very similar result to that described previously in the New Zealand cohort where the negative predictive value for MRI erosions predicting XR erosions after 1 year was 0.91 [7]. The reason why the positive predictive values were so low in the Mundwiler cohort was that this group hardly eroded at all. Only five new XR erosions actually formed for the entire group over the 24-month period, presumably reflecting the impact of modern disease-suppressing therapies, including anti-TNF agents.

MRI bone edema was a better predictor of erosions, with a positive predictive value of 0.5 at 24 months, and this supports the findings of previous studies at the hand and wrist [2-4]. At the individual joint level, having bone edema dramatically increased the chance of eroding, with an odds ratio of 68.0 at 12 months, although caveats remain regarding confidence intervals due to small numbers. These results also suggest that this risk is reversible (progression to XR erosion did not occur in $50 \%$ of cases), pointing to the

$\mathrm{MRI}=$ magnetic resonance imaging; MTP = metatarsophalangeal; RA = rheumatoid arthritis; TNF = tumor necrosis factor; $\mathrm{XR}=$ radiographic. 


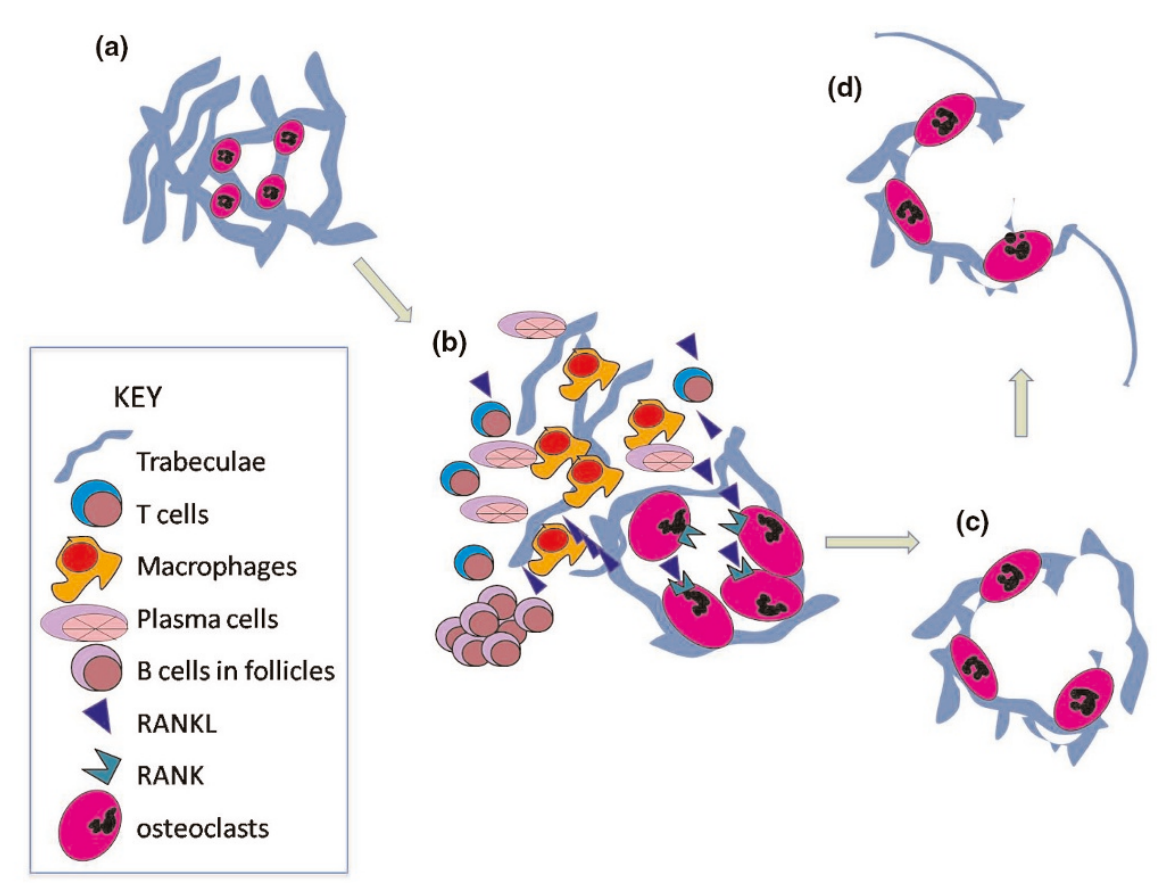

A model of rheumatoid arthritis, implicating subchondral osteitis and RANKL-mediated osteoclastogenesis in the development of bone erosion. (a) Resting subchondral trabecular bone. (b) Osteitis (bone edema on MRI) characterised by infiltrates of macrophages, lymphocytes and plasma cells adjacent to osteoclasts. RANKL staining abundant adjacent to trabeculae [10]. (c) Activated osteoclasts resorb trabecular bone leading to intra-osseous erosion formation (subchondral bone defects on MRI). (d) Cortical bone erosion develops. MRI = magnetic resonance imaging; RANK, receptor activator for nuclear factor $\kappa B$; RANKL, RANK ligand.

influence of therapeutic intervention. When the antecedents to $\mathrm{XR}$ erosions were examined, MRI erosions were detected in $75 \%$ of cases but the other $25 \%$ of scans were also abnormal, revealing bone defects. This class of lesion does not fulfill current criteria for erosion using the rheumatoid arthritis MRI scoring system (RAMRIS), having no cortical break [8]. An early version of this scoring system did include bone defects but the category was later dropped because of poor scoring reliability [9]. Nevertheless, these results suggest that an area of well-defined signal change in the subchondral bone, suggesting trabecular loss, could be significant. A recent study examining the histopathology of bone excised from RA patients at joint replacement revealed high densities of osteoclasts and RANKL (receptor activator for nuclear factor $\kappa B$ ligand) staining adjacent to subchondral bony trabeculae in regions where bone edema was present on preoperative MRI scans [10]. These findings suggest a mechanism for bone loss without breaching the cortical plate, where bone edema might be followed by a subchondral bone defect, which could in turn precede the development of erosion (Figure 1).

What do the findings of Mundwiler and colleagues tell us about the role of synovitis as a pre-erosive lesion? Synovitis was common, being observed in $74 \%$ of cases. It was detected as an isolated finding in 52 MTP joints and in these it resolved in two-thirds of cases without the appearance of other lesions. In one-quarter of cases, synovitis persisted without other lesions appearing, and in only 6\% of MTPs, where it was an initial isolated finding, did bony lesions develop. This would tend to imply that while synovitis is a very common finding in RA, it is not in itself pre-erosive. Its strong association with bone edema (which was accompanied here by synovitis in all but one instance) suggests that the lesions are often linked but this is not invariable. In those patients with pure synovitis and without bone edema, the prognosis may be more favourable. Further studies to follow the progress of these 'good prognosis' patients are warranted as the 'hit hard and early' treatment philosophy may not serve in their best interests. Conversely, the appearance of definite bone edema needs to serve as a red flag for rheumatologists and active management with powerful anti-erosive medications such as TNF inhibitors should be considered urgently for these patients.

\section{Competing interests}

The authors declare that they have no competing interests. 


\section{References}

1. Mundwiler ML, Maranian $\mathrm{P}$, Brown DH, Silverman JM, Wallace D, Khanna D, Louie J, Furst DE, Weisman MH: The utility of MRI in predicting radiographic erosions in the metatarsophalangeal joints of the rheumatoid foot: a prospective longitudinal cohort study. Arthritis Res Ther 2009, 11:R94.

2. McQueen FM, Benton N, Perry D, Crabbe J, Robinson E, Yeoman $S$, McLean L, Stewart N: Bone edema scored on magnetic resonance imaging scans of the dominant carpus at presentation predicts radiographic joint damage of the hands and feet six years later in patients with rheumatoid arthritis. Arthritis Rheum 2003, 48:1814-1827.

3. Haavardsholm EA, Boyesen P, Ostergaard M, Schildvold A, Kvien $\mathrm{T}$ : Magnetic resonance imaging findings in 84 patients with early rheumatoid arthritis: bone marrow oedema predicts erosive progression. Ann Rheum Dis 2008, 67:794-800.

4. Hetland ML, Ejbjerg B, Hørslev-Petersen K, Jacobsen S, Vestergaard A, Jurik AG, Stengaard-Pedersen $K$, Junker $P$, Lottenburger T, Hansen I, Andersen LS, Tarp U, Skjødt H, Pedersen JK, Majgaard $\mathrm{O}$, Svendsen AJ, Ellingsen $\mathrm{T}$, Lindegaard $\mathrm{H}$, Christensen AF, Vallø J, Torfing T, Narvestad E, Thomsen HS, Ostergaard M; CIMESTRA study group: MRI bone oedema is the strongest predictor of subsequent radiographic progression in early rheumatoid arthritis. Results from a 2-year randomised controlled trial (CIMESTRA). Ann Rheum Dis 2009, 68:384-390.

5. Hulsmans HM, Jacobs JW, van der Heijde DM, van AlbadaKuipers GA, Schenk Y, Bijlsma JW: The course of radiologic damage during the first six years of rheumatoid arthritis. Arthritis Rheum 2000, 43:1927-1940.

6. Ostendorf B, Scherer A, Modder U, Schneider M: Diagnostic value of magnetic resonance imaging of the forefeet in early rheumatoid arthritis when findings on imaging of the metacarpophalangeal joints of the hands remain normal. Arthritis Rheum 2004, 50:2094-2102.

7. McQueen FM, Stewart N, Crabbe J, Robinson E, Yeoman S, Tan $\mathrm{PL}$, McLean $\mathrm{L}$ : Magnetic resonance imaging of the wrist in early rheumatoid arthritis reveals progression of erosions despite clinical improvement. Ann Rheum Dis 1999, 58:156163.

8. Østergaard M, Peterfy C, Conaghan $\mathrm{P}, \mathrm{McQueen} F$, Bird $\mathrm{P}$, Ejbjerg B, Shnier R, O'Connor P, Klarlund M, Emery P, Genant H, Lassere M, Edmonds J: OMERACT Rheumatoid Arthritis Magnetic Resonance Imaging Studies. Core set of MRI acquisitions, joint pathology definitions, and the OMERACT RA-MRI scoring system. J Rheumatol 2003, 30:1385-1386.

9. Lassere M, McQueen F, Østergaard M, Conaghan P, Shnier R, Peterfy C, Klarlund M, Bird P, O'Connor P, Stewart N, Emery P, Genant H, Edmonds J: OMERACT Rheumatoid Arthritis Magnetic Resonance Imaging Studies. Exercise 3: an international multicenter reliability study using the RA-MRI Score. J Rheumatol 2003, 30:1366-1375.

10. Dalbeth N, Smith T, Gray S, Doyle A, Antill P, Lobo M, Robinson E, King A, Cornish J, Shalley G, Gao A, McQueen FM: Cellular characterisation of magnetic resonance imaging bone oedema in rheumatoid arthritis; implications for pathogenesis of erosive disease. Ann Rheum Dis 2009, 68:279-282. 